\title{
Bladder-wall and pelvic-plexus stimulation with model microstimulators: Preliminary observations
}

\author{
James S. Walter, PhD; ${ }^{1-2 *}$ Mary Pat Fitzgerald, MD; ${ }^{2}$ John S. Wheeler, MD; ${ }^{2-3}$ Bradley Orris, MD; ${ }^{2-3}$ \\ Allison McDonnell; ${ }^{1}$ Robert D. Wurster, PhD $^{1,4-5}$ \\ ${ }^{1}$ Research Service, Department of Veterans Affairs (VA) Edward Hines Jr. Hospital, Hines, IL; ${ }^{2}$ Department of \\ Urology, Loyola Medical Center, Stritch School of Medicine, Maywood, IL; ${ }^{3}$ Surgical Service, VA Edward Hines Jr. \\ Hospital, Hines, $I L ;{ }^{4}$ Department of Physiology and ${ }^{5}$ Department of Neurosurgery, Loyola Medical Center, Stritch \\ School of Medicine, Maywood, IL
}

\begin{abstract}
Severe urinary retention is not a common condition, but may occur following some pelvic surgeries or other medical conditions. Electrical stimulation of the bladder has been examined as a means of managing this difficult problem. We conducted preliminary investigations in cats to prove the hypothesis that pelvic-plexus (bladder-neck) stimulation would produce greater micturition response with reduced side effects, such as animal movement or discomfort, than bladder-wall stimulation with electrodes implanted higher on the bladder wall. We used model microstimulators that mimic the look and function of commercial microstimulators, but that we constructed. We instrumented four female cats during a survival surgery. Animals recovered well and studies were conducted over a 1-month period in the conscious animal and under anesthesia. We performed a variety of studies with different stimulation parameters and electrode locations to evaluate our hypothesis. In the active animal, we supplied only low currents, but two animals responded to stimulation with bladder contractions and voiding. Following anesthesia, higher stimulating currents resulted in greater bladder contractions during stimulation in two of the three animals. In two cases, pelvic-plexus (bladder-neck) stimulation induced greater micturition responses than direct bladderwall stimulation. In conclusion, we learned from these preliminary observations that stimulation at the pelvic plexus (bladder neck) may induce a better micturition response than stimulation higher on the bladder-wall. Newly available commercial microstimulators should be further studied for the treatment of urinary retention.
\end{abstract}

Key words: bladder, cystometry, electrical stimulation, electromyography, micturition, neuromodulation, urinary, urinary retention, urodynamics, veterans.

\section{INTRODUCTION}

Urinary retention occurs for a variety of reasons, including spinal cord injury (SCI), extensive pelvic or anorectal surgeries, severe diabetes, and idiopathic causes. For example, some veterans have urinary retention following abdominoperineal resection for colon cancer, which disrupts many of the nerves that innervate the bladder. Individuals with refractory urinary retention usually have to conduct intermittent catheterization or use indwelling catheters to empty their bladders. Both of these methods are bothersome and are associated with urinary tract infections and other complications [1]. Electrical stimulation may allow for urination without catheters.

\footnotetext{
Abbreviations: $\mathrm{EMG}=$ electromyography, $\mathrm{m}$-micro $=$ model microstimulators, $\mathrm{pps}=$ pulses per second, $\mathrm{RF}=$ radio frequency, SCI = spinal cord injury, SD = standard deviation.

This material was based on work supported by the Office of Research and Development, Rehabilitation Research and Development Service, Department of Veterans Affairs (B2930P).

* Address all correspondence to James S. Walter, PhD; Edward Hines Jr. Veterans Affairs Hospital (151) Research Service, Hines, IL 60141; 708-202-5805; fax: 708-202-2319. Email: James.Walter@med.va.gov
}

DOI: 10.1682/JRRD.2004.02.0014 
One effective stimulation method is neuromodulation with an electrode implanted adjacent to the third sacral nerve root at its foramen. Approximately 50 percent of patients tested and implanted for management of urinary retention have been able to regain voiding function [2]. Another stimulation approach not currently in clinical use is direct bladder-wall or pelvic-plexus stimulation. These approaches directly induce bladder contractions, either through stimulation of the motor nerves to the bladder or activation of micturition reflexes through stimulation of bladder sensory fibers [3-6].

End-organ stimulation at the bladder wall or the pelvic plexus has primarily been studied for refractory urinary retention following SCI [4-8]. Clinical investigations in this area have shown problems in some patients, including pain, increased urethral resistance, and ineffective micturition [6-9]. Biocompatibility concerns with patient and animal implants have also been reported [7-9]. We have conducted animal studies in this area and recently reported that a suture electrode that extends across the plexus of nerves innervating the bladder was effective in inducing micturition [3,10-11]. We performed these studies both before and after SCI in the active animal. Other reports of end-organ stimulation exist [12]. A recent study has cited the benefit of stimulation of the bladder wall with electrodes on the end of a urethral catheter in the bladder in children [13]. Urinary retention in these individuals was due to a variety of disorders, and periodic stimulation resulted in improved micturition.

A major advance in the field of neuroprosthetics has been the introduction of microstimulators (Advanced Bionics, Sylimar, CA; Alfred E. Mann Foundation, Valencia, CA), which may be applied to stimulation for urinary retention [14-19]. These small devices are less than $2.7 \mathrm{~cm}$ in length and less than $3 \mathrm{~mm}$ in diameter and have two electrodes, one on each end of the device. External coils provide power with radio frequency (RF) energy or with an internal battery. The devices can be implanted with minimally invasive procedures and are controlled externally with an RF control device. These devices could be considered for end-organ stimulation of the urinary bladder. We previously reported no migration and minimal connective tissue growth on these devices implanted on the bladder wall for a 3-month period in animals [20].

For the current pilot study, we used model microstimulators (m-micros), which are devices that look and function like commercial microstimulators but have connecting wires tethered to external stimulators [21]. We implanted these devices on the bladder wall and pelvic plexus (bladder neck). We hypothesized that pelvicplexus stimulation at the bladder neck would be more effective than stimulation higher on the bladder wall in terms of a greater micturition response with reduced side effects.

\section{MATERIAL AND METHODS}

We compared the location of stimulation electrodes and the effects of various stimulating parameters for inducing bladder contractions in an animal model. We detailed the methods of making m-micros and animal instrumentation methods elsewhere [21].

\section{Animal Care and Maintenance}

We studied four conditioned adult female cats from commercial vendors ranging in body weight from 3 to $4 \mathrm{~kg}$. Each animal had a 2-week quarantine. The cats were maintained with environmental enrichment at all times. This study received Animal Studies Committee approval for ethical care of the animals and methods of device implantation. Housing for these animals was in individual stainlesssteel cages in rooms with temperature and photoperiod control at Hines Hospital Animal Research Facility (Hines, IL) (accredited by the International Association for Assessment and Accreditation of Laboratory Animal Care).

\section{Instrumentation}

The m-micros were made from Silastic silicone rubber tubing (Dow Corning Corporation, Auburn, MI) and multistranded stainless-steel cable [21]. The devices included positive and negative electrodes for bipolar stimulation. The electrodes were constructed from 20-stranded, 1 mil (1/1000 in.) stainless-steel wire (316LVM Cooner Wire Inc., Chatworth, CA) coated with Teflon insulation. The wire was stripped of insulation and the exposed portion formed into a rounded ball. We placed these ball electrodes at each end of $10 \mathrm{~mm}$ of Silastic tubing and secured them with medical grade Silastic adhesive. Instrumentation for urodynamics evaluation included urethral and anal electromyography (EMG), bladder pressure, and abdominal pressure measurements. EMG recording electrodes were created from the same insulated wire and the uninsulated end placed in a 20 gauge needle for insertion into the muscle of the pelvic floor. Two small-diameter Silastic tubes were implanted into the bladder to allow for bladder filling, 
emptying, and pressure measurement. A balloon catheter in the abdomen recorded abdominal pressure.

\section{Surgery}

We conducted an initial instrumentation surgery to implant the m-micros and lower urinary-tract monitoring devices. Animals were sedated (intramuscular ketamine hydrochloride $20 \mathrm{mg} / \mathrm{kg}$ ), followed by inhalation anesthesia (1.5\%-2.5\% sevoflurane). To implant the m-micro on the pelvic plexus, we surgically exposed the bladder via a midline incision and sutured the devices to the fat pads adjacent to the urethra approximately $1 \mathrm{~cm}$ distal to the bladder neck. We previously reported that at autopsy, these implants placed distal to the bladder neck were all found located on the fat pad at the bladder neck [21]. We determined that the devices had moved to this location during the implantation as the bladder was returned to its natural position. We describe throughout this paper that the pelvic-plexus stimulation site for the m-micro was a pelvic-plexus (bladder-neck) location. We sutured two additional m-micros to the bladder wall above the ureters. A polypropylene (3-0) suture secured each m-micro. We inserted two EMG electrodes under the pubic bone adjacent to the striated urethral sphincter, and inserted two electrodes in the anal sphincter. We placed a final EMG electrode under the skin in the back as a grounding electrode. We sutured the bladder catheters into the dome of the bladder for bladder filling and pressure recording. We then tunneled and exteriorized electrode leads and catheters from the back below the shoulders and placed them in an animal jacket.

\section{Postoperative Procedures and Studies}

All the animals received antibiotics for 5 days and analgesics for 3 days or more as needed following surgery. The animals had small functional capacity bladders caused by irritation after instrumentation and were given oxybutynin (1.5 mg twice a day) to increase their bladder capacity. Oxybutynin was not given when studies were being conducted. Cats 3 and 4 developed urinary tract infections that were treated with oral antibiotics.

We conducted studies in active animals 2 to 4 weeks following the instrumentation. Urodynamics parameters recorded on an 8-channel recorder (Astromed, West Warwick, RI) included bladder and abdominal pressures, animal activity recorded with a pressure transducer connected to the animal's jacket, urethral and anal EMG, and volume voided. The first study we performed was cystome- try, with the bladder filling at $5 \mathrm{~mL} / \mathrm{min}$ until micturition occurred. Urine was collected in a funnel under the animal's cage, and the weight of the fluid was recorded as a measure of volume voided. Our testing showed an average $1.4 \mathrm{~s}$ delay from the time the urine was expelled before reaching the recording transducer that recorded the volume by weight. This delay was due to the approximately $22 \mathrm{in}$. between the animal and the collection beaker.

Our stimulation studies compared the m-micro on the bladder wall and pelvic plexus (bladder neck). We tested both unilateral and bilateral electrodes with an initial bladder volume one-half to two-thirds of cystometric capacity. We used two stimulators (S48, Grass, Quincy, MA) that included isolation, constant current, and capacitor-coupled pulsing. Stimulating parameters we used to compare the m-micros included a 3-s stimulation period, 40 pulses per second (pps) stimulation frequency, $0.3 \mathrm{~ms}$ pulse durations, and a current-response protocol. For this protocol, we increased the current from $1 \mathrm{~mA}$ to a maximum of $40 \mathrm{~mA}$, and measured bladder pressure responses. Any side effects of stimulation, including animal vocalization, significant animal movement, or any other signs of discomfort resulted in discontinuation of the stimulation and further studies only at lower currents. Additionally, we found $1 \mathrm{~ms}$ pulse durations effective in some preliminary observations (data not shown). We showed some of the results with $1 \mathrm{~ms}$ pulse rather than the standard $0.3 \mathrm{~ms}$ pulse durations. For presentation of the current-response studies, we used a single current from the current-response study. It was the current that induced a strong bladder contraction with limited adverse effects. This is a current strength that might be considered important for clinical applications. Our additional studies included comparison of the m-micro stimulation during anesthesia $(11 \mathrm{mg} / \mathrm{kg}$ ketamine and $0.75 \mathrm{mg} / \mathrm{kg}$ xylazine), which was performed on three of the four animals. During this protocol, we increased currents until moderate adverse responses were observed, such as body, leg, or abdominal movement. For the final study, we conducted fluoroscopic observation of the lower urinary tract during spontaneous bladder contractions and stimulationinduced voiding. Statistical results are presented as mean \pm standard deviation (SD).

\section{RESULTS}

In Figure 1 (Cat 1), we show spontaneous bladder contractions during cystometry before and after anesthesia. 
(a)
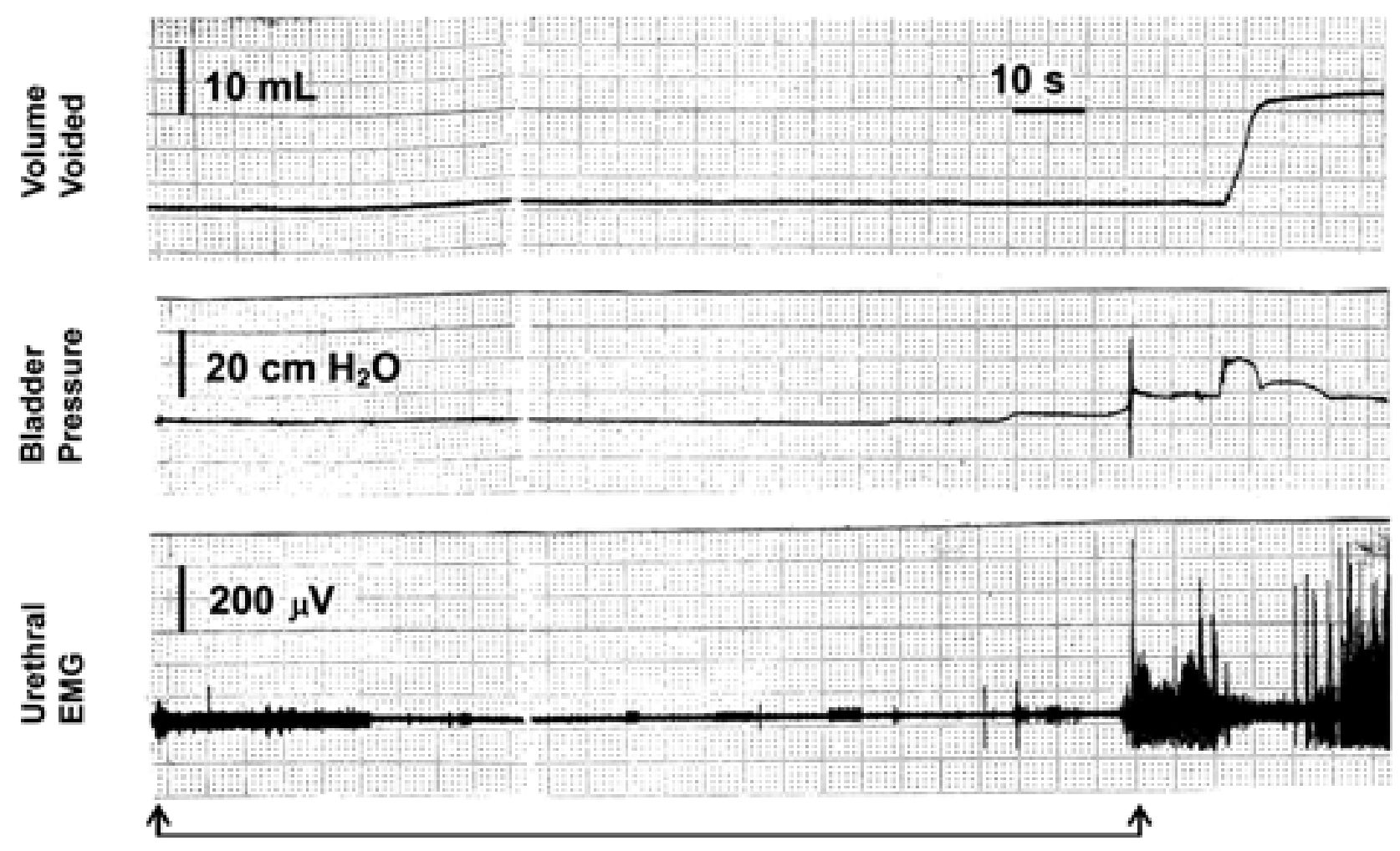

Bladder Filling 0 to $12 \mathrm{~mL}$

(b)

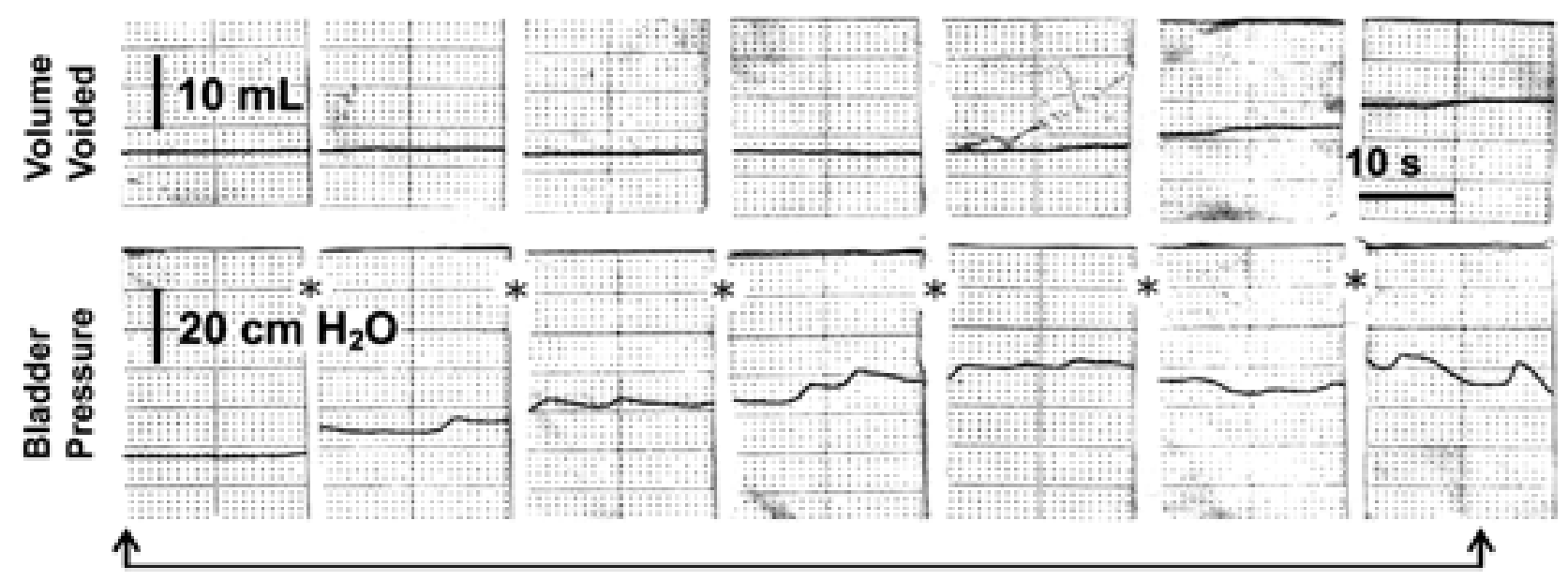

\section{Bladder Filling 0 to $20 \mathrm{~mL}$}

Figure 1.

Urodynamic responses to bladder filling (cystometry) in Cat 1: (a) Before anesthesia, at filling volume of $12 \mathrm{~mL}$, bladder contraction of $11 \mathrm{~cm}$ $\mathrm{H}_{2} \mathrm{O}$ results in $16 \mathrm{~mL}$ voiding at maximal rate of $6 \mathrm{~mL} / \mathrm{s}$. Urethral electromyography (EMG) is reduced during voiding and no residual volume remained. Before filling began, $4 \mathrm{~mL}$ was present. (b) After anesthesia, at filling volume of $20 \mathrm{~mL}$, bladder contractions are inhibited and bladder compliance is decreased, with baseline pressure as high as $24 \mathrm{~cm} \mathrm{H}_{2} \mathrm{O}$ and voiding at low rate. Volume voided was $10 \mathrm{~mL}$ and residual volume was $10 \mathrm{~mL}$. $10 \mathrm{~s}$ cuts in record for presentation. 
Before anesthesia (Figure 1(a)), a spontaneous bladder contraction occurs at a filling volume of $12 \mathrm{~mL}$, and with a bladder contraction of $11 \mathrm{~cm} \mathrm{H}_{2} \mathrm{O}$. Cat 1 voided $16 \mathrm{~mL}$, with a maximal flow rate of $6 \mathrm{~mL} / \mathrm{s}$. Since no residual volume occurred at the end of this void, bladder volume at the beginning of the cystometry was $4 \mathrm{~mL}$. The animal was in a typical squatting position, and the EMG recording from the urethral sphincter was quieted during voiding. The abdominal pressure recording was not working during this session. However, some evidence exists of increased abdominal pressures by the rapid $10 \mathrm{~cm} \mathrm{H}_{2} \mathrm{O}$ increase in bladder pressure $10 \mathrm{~s}$ before the micturition contraction. After anesthesia (Figure 1(b)), spontaneous bladder contractions were inhibited and compliance was decreased, shown by increased baseline pressures. Bladder filling to $20 \mathrm{~mL}$ shows small bladder contractions and $10 \mathrm{~mL}$ of voiding with a $10 \mathrm{~mL}$ residual volume. The urethral EMG recording following anesthesia was too small to be interpreted.

In Table 1, we summarize the cystometry results for the four awake animals and three anesthetized animals studied. Again, inhibited micturition response following anesthesia was shown by increased bladder filling and residual volumes, and decreased peak bladder pressures and urine flow rates. The average peak bladder pressures during voiding in the conscious animal were high. These high bladder pressures did not appear to us to be due to contractions of the urethral skeletal sphincter, since the height of the EMG record was reduced during voiding. Prolonged bladder contractions of 15 to $20 \mathrm{~s}$ when the bladder was empty was seen in two of the four animals, and may have been due to bladder irritation from instrumentation. After anesthesia, the bladder filling in all the animals was characterized by poor compliance and multiple small bladder contractions.

Table 1.

Urodynamics response to cystometry in conscious and anesthetized female cat.

\begin{tabular}{|c|c|c|c|c|}
\hline Cat & $\begin{array}{l}\text { Filling* } \\
\text { Volume } \\
\text { (mL) }\end{array}$ & $\begin{array}{c}\text { Peak } \\
\text { Bladder } \\
\text { Pressure } \\
\left(\mathrm{cm} \mathbf{H}_{2} \mathbf{O}\right)\end{array}$ & $\begin{array}{c}\text { Residual } \\
\text { Volume } \\
\text { (mL) }\end{array}$ & $\begin{array}{c}\text { Maximal } \\
\text { Flow Rate } \\
\text { (mL/s) }\end{array}$ \\
\hline $\begin{array}{l}\text { Conscious } \\
(n=4)\end{array}$ & $18.0 \pm 9.1$ & $56.5 \pm 41.1$ & $0.3 \pm 0.5$ & $2.4 \pm 0.5$ \\
\hline $\begin{array}{l}\text { Anesthetized } \\
(n=3)\end{array}$ & $22.3 \pm 5.9$ & $24.7 \pm 3.1$ & $13.7 \pm 4.0$ & $0.3 \pm 0.4$ \\
\hline
\end{tabular}

We show the micturition response to electrical stimulation before anesthesia in Figure 2 (Cat 4). Figure 2 details a series of stimulations from a current-response study with pelvic-plexus (bladder-neck) m-micros. Increasing stimulating current applied at $40 \mathrm{pps}$ for $3 \mathrm{~s}$ on the left side (Figure 2(a)) and then the right side (Figure 2(b)) resulted in increasing peak bladder responses. Bilateral stimulation (Figure 2(c)) resulted in a prolonged bladder contraction with a peak pressure of $60 \mathrm{~cm} \mathrm{H}_{2} \mathrm{O}$ and $5 \mathrm{~mL}$ of voiding. The urethral EMG was not recorded during stimulation, but these records indicated phasic spiking activity during continued elevated bladder pressure following the end of stimulation. The other animals did not show this phasic urethral spiking activity. A strong urethral EMG discharge at the end of the bladder contraction (Figure 2(c)) shows the urethralemptying reflex [7].

We summarize the current-response studies for the two electrode locations in Table 2 (no anesthesia). Results are shown for a stimulating current that induced a maximal bladder pressure with no animal movement or vocalization. We conducted all stimulation with a single $3 \mathrm{~s}$ stimulation period with 40 pps and a pulse duration of $0.3 \mathrm{~ms}$ or $1 \mathrm{~ms}$. Cats 1 and 2 vocalized at a low stimulating current, and we detected no bladder contraction for any of the electrode arrangements. Learned responses to stimulation appeared to be involved in these low stimulation thresholds for vocalization. For example, during initial studies, higher currents were used without any vocalization or discomfort to the animal. After several stimulations, vocalizations started at lower stimulating currents. The vocalizations did not appear to be due to sensitization or electrode movement effects, since currents had to be reduced by more than 50 percent, and on subsequent days only lower currents could be used. We noted that currents as high as 15 to $20 \mathrm{~mA}$ were used in Cat 2 without a bladder response. A side effect of the stimulation at these high currents was increased abdominal pressure.

Cats 3 and 4 responded to stimulation with bladder contractions without vocalizations or movement (Table 2). In these animals, bilateral stimulation was more effective than unilateral stimulation, and pelvicplexus (bladder-neck) stimulation was as good, or better, than bladder-wall stimulation. For Cat 3, stimulation with a single m-micro on the pelvic plexus (bladder neck) induced a bladder pressure of $60 \mathrm{~cm} \mathrm{H}_{2} \mathrm{O}$. Following stimulation (not shown in Table 2), the pressure 

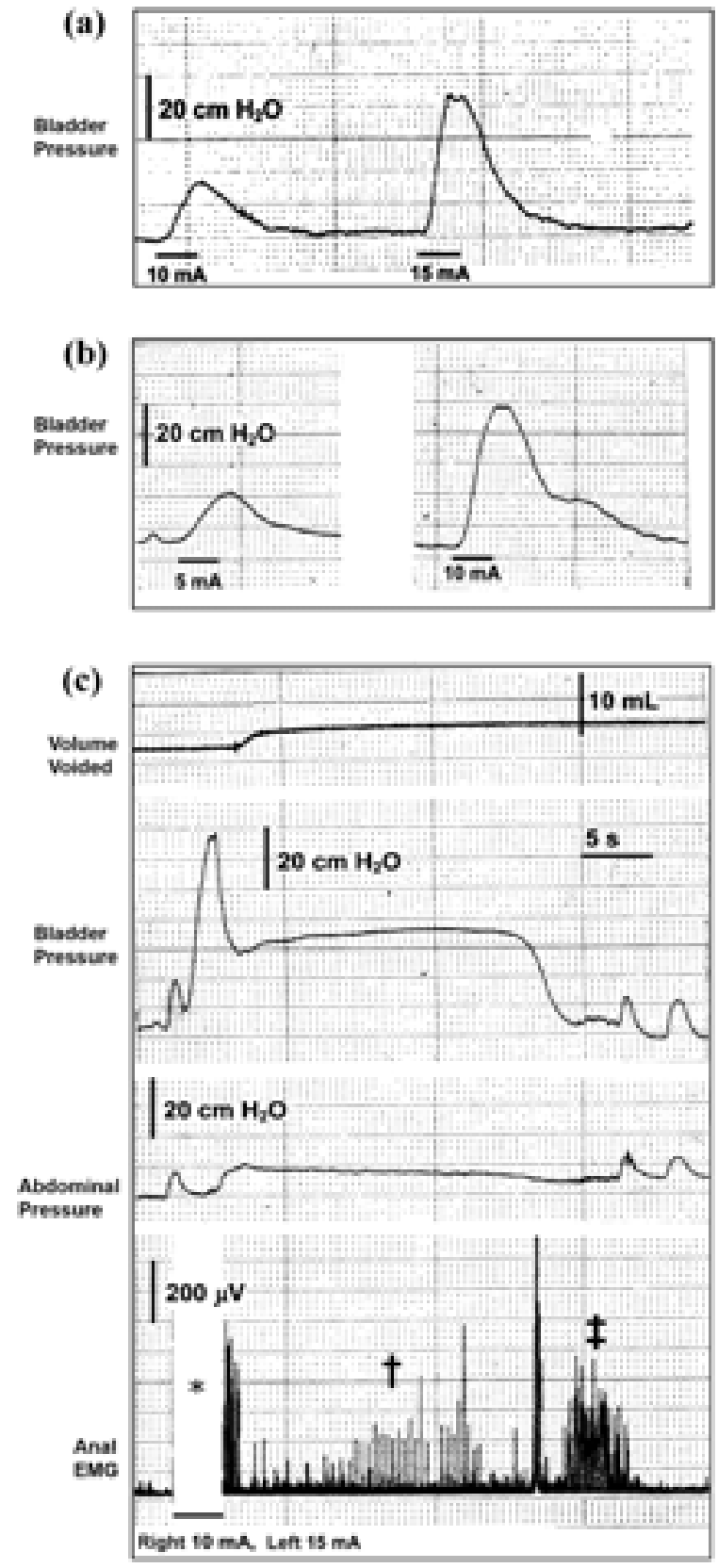

Figure 2.

Current-response studies before anesthesia showing effects of unilateral and bilateral pelvic-plexus stimulation in Cat 4: (a) Leftand (b) right-side stimulation showing increasing bladder responses to higher stimulating currents; (c) bilateral stimulation showing prolonged bladder contraction with voiding. No voiding or changes in electromyographic (EMG) record observed in (a) or (b). All stimulations at $40 \mathrm{pps}$ and $0.3 \mathrm{~ms}$ pulse duration. *EMG record deleted during electrical stimulation due to artifact. ${ }^{\dagger}$ Phasic pattern in anal EMG recording following voiding and during a period of continued elevated bladder pressure. ${ }^{\ddagger}$ High anal EMG discharge showing a urethral emptying reflex at end of bladder contraction. continued to increase to $>100 \mathrm{~cm} \mathrm{H}_{2} \mathrm{O}$ when voiding occurred. The animal took a squatting position during and after stimulation indicating that stimulation was inducing a micturition stance and reflex. Cat 4 showed effective voiding with pelvic-plexus stimulation with a low residual volume. As in Cat 3, a prolonged bladder contraction following the short $3 \mathrm{~s}$ stimulation indicated activation of the micturition reflex. Variable bladder filling volumes are also listed in Table 2 . The small initial volumes of 5 to $10 \mathrm{~mL}$ in Cats 1,2 , and 4 probably reflected an ongoing cystitis that limited bladder filling.

In Table 3, we post results from stimulation following anesthesia in the three animals studied (Cats 1, 2, and 3 ). We compare results from the two electrode locations at a current that induced a maximal bladder pressure with moderate adverse responses, such as increased abdominal pressure or leg movement. These stimulation currents were higher than could be used in the conscious animalinduced bladder contractions. Bilateral stimulation was superior to unilateral stimulation, and pelvic-plexus (bladder-neck) stimulation was as good as or better than bladder-wall stimulation. Cat 3 did not respond to stimulation with as high bladder pressures as observed while conscious. Ketamine and xylazine anesthetics have less effect on cystometric measurements than other anesthetics in rats, and evidence also exists that cats continue to have reflex bladder activity with ketamine anesthetic [22-23]. However, results from Tables $\mathbf{1}$ to $\mathbf{3}$ indicate some decrease in the peak bladder pressure responses to bladder filling or stimulation following anesthesia.

In Figure 3, we show fluoroscopic observations of the lower urinary tract during cystometry in Cat 3. With the bladder filled to near capacity, we saw the radiopaque enter the bladder neck and then advance to the striated urethral sphincter (Figure 3(a) and 3(b)). Voiding followed shortly after when the striated urethral sphincter opened (Figure 3(c)). Voiding passed through a narrow urethral meatus where the urine enters the distal end of the vagina before it is dispelled. We saw examples similar to the description of those found in Figure $\mathbf{3}$ in all four animals. We observed a second pattern of voiding in the animals where the urine passed through the striated urethral sphincter without delay. Fluoroscopic observations of bladder and urethra during and following stimulation (images not shown) appeared similar to the description for spontaneous bladder contractions. Voiding only occurred when the striated urethral sphincter opened. 
Table 2.

Urodynamics responses comparing bladder-wall and pelvic-plexus (bladder-neck) stimulation in conscious animal. We used stimulation at high current, which induced maximal bladder pressure with no adverse responses, such as movement or vocalizing.

\begin{tabular}{|c|c|c|c|c|c|c|c|c|c|}
\hline Organ & $\begin{array}{l}\text { M-Micro } \\
\text { No. } \\
(1 \text { or } 2)^{*}\end{array}$ & $\begin{array}{c}\text { Total No. } \\
\text { Stimulations }^{\dagger}\end{array}$ & $\begin{array}{c}\text { Pulse } \\
\text { Duration } \\
\text { (ms) }\end{array}$ & $\begin{array}{c}\text { Stimulation } \\
\text { Current } \\
\text { (mA) }\end{array}$ & $\begin{array}{c}\text { Peak Bladder } \\
\text { Pressure } \neq \\
\left(\mathbf{c m ~} \mathrm{H}_{2} \mathrm{O}\right)\end{array}$ & $\begin{array}{c}\text { Peak Abdominal } \\
\text { Pressure } \\
\left(\mathrm{cm} \mathrm{H_{2 }} \mathrm{O}\right)\end{array}$ & $\begin{array}{c}\text { Voided } \\
\text { Volume } \\
(\mathrm{mL})\end{array}$ & $\begin{array}{c}\text { Residual } \\
\text { Volume } \\
\text { (mL) }\end{array}$ & $\begin{array}{l}\text { Movement } \\
\text { Responses }\end{array}$ \\
\hline \multicolumn{10}{|l|}{ Cat 1} \\
\hline BW & 1 & 10 & 0.3 & 5 & 0 & 0 & 0 & 10 & None \\
\hline BW & 2 & 3 & 0.3 & $4 / 3$ & 0 & 0 & 0 & 10 & None \\
\hline $\mathrm{PP}$ & 1 & 10 & 0.3 & 5 & 0 & 0 & 0 & 10 & None \\
\hline PP & 2 & 2 & 0.3 & $5 / 2$ & 0 & 0 & 0 & 10 & None \\
\hline \multicolumn{10}{|l|}{ Cat 2} \\
\hline BW & 1 & 23 & 0.3 & 15 & 0 & 0 & 0 & 5 & None \\
\hline BW & 2 & 3 & 0.3 & $13 / 15$ & 5 & 5 & 0 & 5 & None \\
\hline PP & 1 & 21 & 0.3 & 20 & 0 & 3 & 0 & 5 & None \\
\hline PP & 2 & 3 & 0.3 & $20 / 3$ & 10 & 10 & 0 & 5 & None \\
\hline \multicolumn{10}{|l|}{ Cat 3} \\
\hline BW & 1 & 19 & 0.3 & 15 & 12 & 0 & 0 & 30 & None \\
\hline BW & 2 & 2 & $0.3 / 1.0$ & $15 / 20$ & 20 & 5 & 0 & 30 & None \\
\hline PP & 1 & 33 & 0.3 & 15 & $60^{\S}$ & 0 & 17 & 3 & None \\
\hline $\mathrm{PP}$ & 2 & NR & NR & NR & NR & NR & NR & NR & \\
\hline \multicolumn{10}{|l|}{ Cat 4} \\
\hline BW & 1 & 39 & 1.0 & 20 & 42 & 0 & 0 & 5 & Mict Stance \\
\hline BW & 2 & 7 & $0.3 / 1.0$ & $15 / 20$ & 55 & 0 & 0 & 5 & None \\
\hline $\mathrm{PP}$ & 1 & 26 & 1.0 & 10 & $65^{\pi}$ & 0 & 4 & 1 & Mict Stance \\
\hline PP & 2 & 6 & $0.3 / 1.0$ & $15 / 10$ & $65^{\pi}$ & 0 & 4 & 1 & Slight \\
\hline \multicolumn{10}{|c|}{ 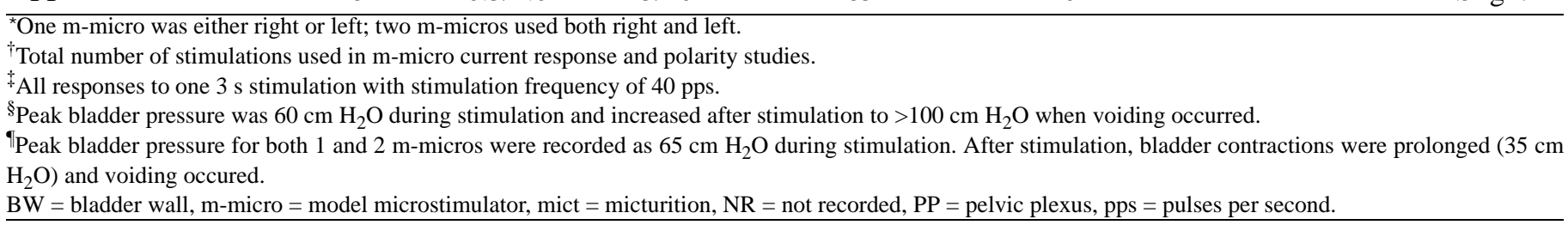 } \\
\hline
\end{tabular}

\section{DISCUSSION}

For this pilot study, we looked at effects of stimulation of the bladder with model microstimulators in a conscious animal model. We associated several factors with inducing high bladder pressures. First, we could induce contractions only in animals that did not vocalize or move in response to stimulation at low currents. Second, with one exception, we found bilateral stimulation more effective than unilateral stimulation. Third, we discovered the pelvic-plexus (bladder-neck) location was as effective, or more effective, than the bladder-wall location, except in a single animal under anesthesia. We observed voiding during stimulation in the conscious animal at this site in two of four animals. Both bilateral stimulation and sites near the bladder neck or base of the bladder have been cited as important locations for bladder stimulation [4-5,11-12,23-24]. However, potential concerns arise over stimulation at the bladder neck or base of the bladder in humans. Stimulation at this site may induce bladder neck closure, causing urethral obstruction [8-9]. Clinical application of microstimulators may require placement of electrodes higher on the bladder wall.

The protocol we used in this study is a poststimulation protocol, where stimulation is applied for a short period ( $3 \mathrm{~s}$ ), at a high frequency (40 pps), and at the highest current that does not result in any discomfort to the animal. These parameters are similar to previous reports of effective stimulation protocols with end-organ stimulation $[4,6-8,24]$. The stimulation may induce micturition reflexes. The sustained bladder contraction after the end 
JRRD, Volume 42, Number 2, 2005

Table 3.

Urodynamics responses comparing bladder-wall and pelvic-plexus stimulation with anesthesia. Stimulation at high current induced maximal bladder pressure with not more than moderate abdominal or leg movement.

\begin{tabular}{|c|c|c|c|c|c|c|c|c|c|}
\hline Organ & $\begin{array}{l}\text { M-micro } \\
\text { No. } \\
(1 \text { or } 2)^{*}\end{array}$ & $\begin{array}{c}\text { Total No. } \\
\text { Stimulations }^{\dagger}\end{array}$ & $\begin{array}{c}\text { Pulse } \\
\text { Duration } \\
\text { (ms) }\end{array}$ & $\begin{array}{c}\text { Stimulation } \\
\text { Current } \\
\text { (mA) }\end{array}$ & $\begin{array}{c}\text { Peak Bladder } \\
\text { Pressure } \ddagger \\
\left(\mathbf{c m ~ H _ { 2 }} \mathbf{O}\right)\end{array}$ & $\begin{array}{c}\text { Peak Abdominal } \\
\text { Pressure } \\
\left(\mathrm{cm} \mathrm{H}_{2} \mathrm{O}\right)\end{array}$ & $\begin{array}{c}\text { Voided } \\
\text { Volume } \\
\text { (mL) }\end{array}$ & $\begin{array}{c}\text { Residual } \\
\text { Volume } \\
(\mathrm{mL})\end{array}$ & Movement \\
\hline \multicolumn{10}{|l|}{ Cat 1 } \\
\hline BW & 1 & 49 & 0.3 & 15 & 28 & NR & 0 & 10 & $\begin{array}{c}\text { Moderate } \\
\text { Abdominal }\end{array}$ \\
\hline BW & 2 & 10 & $0.3 / 0.3$ & $15 / 10$ & 30 & NR & 0 & 10 & $\begin{array}{c}\text { Moderate } \\
\text { Abdominal }\end{array}$ \\
\hline PP & 1 & 35 & $0.3 / 0.3$ & 10 & 28 & NR & 0 & 10 & $\begin{array}{c}\text { Moderate } \\
\text { Abdominal }\end{array}$ \\
\hline PP & 2 & 17 & $0.3 / 0.3$ & $10 / 10$ & 55 & NR & 0 & 10 & $\begin{array}{c}\text { Moderate } \\
\text { Abdominal }\end{array}$ \\
\hline \multicolumn{10}{|l|}{ Cat 2} \\
\hline BW & 1 & 18 & 0.3 & 40 & 12 & NR & 0 & 7 & $\begin{array}{c}\text { Moderate } \\
\text { Abdominal }\end{array}$ \\
\hline BW & 2 & 2 & $0.3 / 0.3$ & $30 / 40$ & 30 & NR & 2 & 5 & $\begin{array}{c}\text { Moderate } \\
\text { Abdominal }\end{array}$ \\
\hline PP & 1 & 27 & 0.3 & 20 & 20 & NR & 0 & 7 & $\begin{array}{c}\text { Moderate } \\
\text { Abdominal }\end{array}$ \\
\hline PP & 2 & 2 & $0.3 / 0.3$ & $20 / 40$ & 25 & NR & 2 & 5 & $\begin{array}{l}\text { Moderate } \\
\text { Abdominal }\end{array}$ \\
\hline \multicolumn{10}{|l|}{ Cat 3} \\
\hline BW & 1 & 23 & 1.0 & 30 & 26 & 2 & 1 & 12 & NR \\
\hline $\mathrm{BW}^{\S}$ & 2 & 3 & $0.3 / 1.0$ & $30 / 25$ & $30^{\S}$ & 5 & 7 & 6 & NR \\
\hline PP & 1 & 18 & 1.0 & 20 & $18^{\mathbb{1}}$ & 10 & 10 & 3 & NR \\
\hline PP & 2 & 3 & $0.3 / 0.3$ & $15 / 30$ & $15^{\mathbb{9}}$ & 15 & 8 & 5 & NR \\
\hline 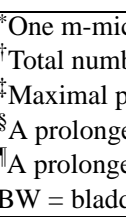 & $\begin{array}{l}\text { cro was either } \\
\text { ber of stimulat } \\
\text { eeak bladder p } \\
\text { ed contraction } \\
\text { ed contraction } \\
\text { der wall, mict }\end{array}$ & $\begin{array}{l}\text { the right or the left; } \\
\text { tions used in m-micr } \\
\text { ressure recorded dur } \\
\text { with a bladder pres } \\
\text { with a bladder pres } \\
=\text { micturition, NR = }\end{array}$ & $\begin{array}{l}\text { two m-micros } \\
\text { o current respo } \\
\text { ring studies that } \\
\text { sure of } 35 \mathrm{~cm} \mathrm{H} \\
\text { sure of } 45 \mathrm{~cm} \mathrm{H} \\
\text { not recorded, }\end{array}$ & $\begin{array}{l}\text { d both the rig } \\
\text { and polarity } \\
\text { ly gave mode } \\
\text { occurred wit } \\
\text { occurred wit } \\
=\text { pelvic plexu }\end{array}$ & $\begin{array}{l}\text { ht and the left. } \\
\text { studies. All stimulat } \\
\text { rate, slight, or no ab } \\
\text { h voiding after stim } \\
\text { h voiding after stimı } \\
\text { s (bladder neck), pp }\end{array}$ & $\begin{array}{l}\text { ions for } 3 \mathrm{~s} \text { and at } 40 \mathrm{pp} \\
\text { dominal or leg moveme } \\
\text { ulation. } \\
\text { lation. } \\
\mathrm{s}=\text { pulses per second. }\end{array}$ & & & \\
\hline
\end{tabular}

of stimulation (Figure 2 and Table 2, Cats 3 and 4) indicates to us a strong micturition reflex component to the responses.

For this paper, we provide an important description of lower urinary tract function in this animal model. First, there is a long urethra, 4 to $5 \mathrm{~cm}$, resulting in a bladder that is high in the abdominal area. This can be contrasted to the human, where the bladder lies directly above the pelvic floor. Bladder-wall electrodes in the cat are some distance from the pelvic floor and would be less likely to induce pelvic floor contraction from current spread than in humans. Second, male cats, dogs, and rats have a phasic voiding pattern not seen in these female cats [1112,25-26). In Figure 2(c), we show that the female cat has the potential for phasic pelvic floor activity. Spiking occurs in the EMG record after voiding and during continued elevated bladder pressures. In addition, the large EMG response when the bladder pressure declined shows strong urethral closure activity similar to responses reported for other quadruped animals [11-12]. Third, our fluoroscopic observations indicated that the long urethra from the bladder neck to the striated urethral sphincter was passive and opened with increased bladder pressure. The striated urethral sphincter regulated urine flow both during spontaneous and stimulation-induced voiding.

Several features of the m-micro are important and warrant further use in preclinical research. The device is simple to implant. The electrode remained secured on the bladder wall or fat pads at the bladder neck and did not 
(a)

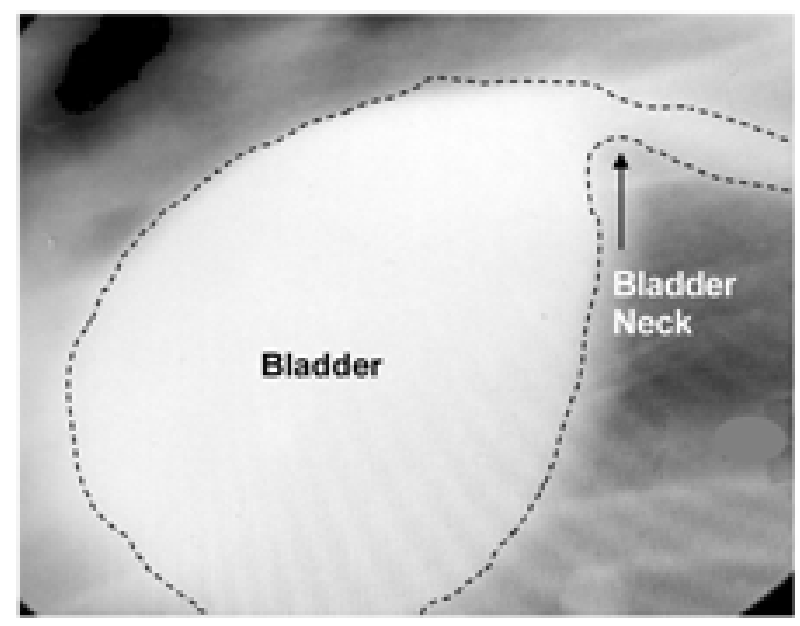

(b)

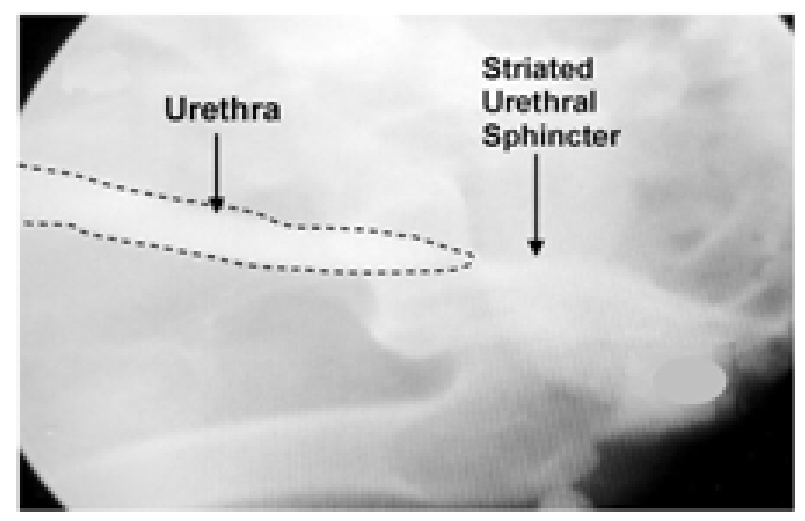

(c)

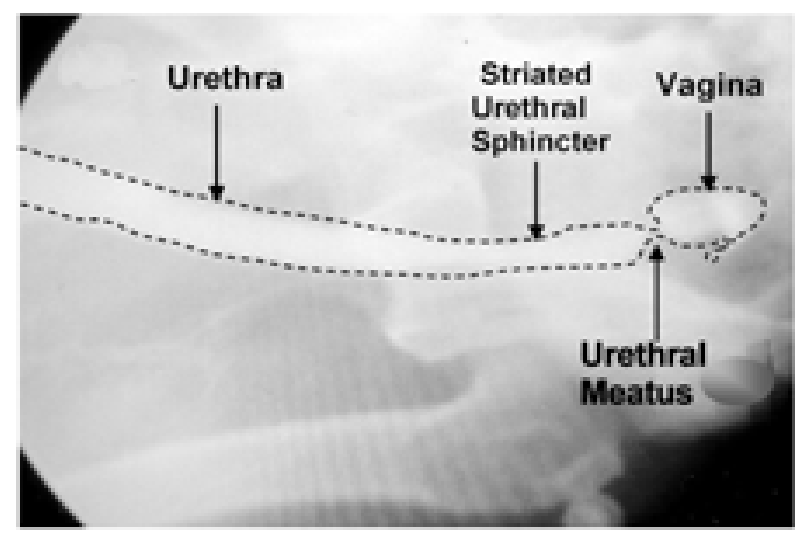

Figure 3.

Fluoroscopic observation of lower urinary tract during bladder filling (Cat 3): (a) bladder filling to near cystometric capacity results in opening of bladder neck and at same time, (b) urine extends to striated urethral sphincter, and (c) short period after, skeletal urethral sphincter opens, resulting in voiding. Narrow urethral meatus is shown.

have some of the erosion and migration problems previously reported for devices implanted on the bladder wall $[8,10,27]$. However, the period of implantation in this study was only a few months. We previously reported autopsy results for these animals that showed extensive connective tissue growth on the bladder walls, which is associated with the extensive instrumentation used in these studies [21]. This observation is in contrast to our prior study with commercial microstimulators on the bladder wall [20]. In that study, we observed very little encapsulation response on the bladder wall.

A potential disadvantage of the m-micro electrode is its small size. It does not extend over a larger portion of the bladder wall containing dispersed pelvic-plexus nerves. We previously reported that a suture electrode extended over a large portion of the bladder base was an effective electrode [11-12]. Stimulation in five conscious male cats with intact spinal cords resulted in micturition in all the animals. Thus, we propose future studies to compare suture electrodes and microstimulator electrodes in the same animal model.

\section{CONCLUSIONS}

Electrical stimulation to the bladder or pelvic plexus has the potential to be an important new method for management or urinary retention. Our preliminary observations indicate that stimulation of the pelvic plexus is more effective than direct bladder stimulation. In two of the four animals in this study, this location was effective for inducing bladder contractions and voiding with a minimum of side effects. M-micro or commercial microstimulators should continue to be investigated for promoting micturition reflexes for conditions such as refractory urinary retention. These devices have important advantages, such as small size, allowing implantation with minimally invasive techniques. Future work should further investigate effective stimulation protocols. In particular, a comparison needs to be conducted between long suture electrodes and small microstimulator electrodes for inducing bladder contractions with a minimum of side effects.

\section{REFERENCES}

1. Tanagho EA, McAninch JW, editors. Smith's general urology. 14th ed. West Norwalk (CT): Appleton and Lange Inc.; 1995. p. 797. 
2. DasGupta R, Fowler CJ. Urodynamic study of women in urinary retention treated with sacral neuromodulation. J Urol. 2004;171(3):1161-64.

3. Walter JS, Wheeler J, Cogan S, Plishka M, Riedy LW, Wurster RD. Evaluation of direct bladder stimulation with stainless steel woven eye electrodes. J Urol. 1993;150(6): 1990-96.

4. Magasi P, Simon Z. Electrical stimulation of the bladder and gravidity. Urol Int. 1986;41:241-45.

5. Magasi P, Novoszel T, Koncz P. Electronic bladder stimulation in spinal cord paralysis. Urol Int. 1976;31(5):332-42.

6. Kaeckenbeeck B. Electrostimulation of the bladder in paraplegia. Acta Urol Belg. 1979;47(1):139-40.

7. Halverstadt DB, Parry WL. Electrical stimulation of the human bladder: 9 years later. J Urol. 1975;113(3):341-44.

8. Jonas U, Hohenfellner R. Late results of bladder stimulation in 11 patients: followup to 4 years. J Urol. 1978;120(5): 565-68.

9. Koldewijn E, Van Kerrebroeck E, Schaafsma E. Bladder pressure sensors in an animal model. J Urol. 1992;151: 1376-84.

10. Walter JS, Wheeler JS, Cai W, Wurster RD. Direct bladder stimulation with suture electrodes promotes voiding in a spinal animal model: a technical report. J Rehabil Res Dev. 1997;34(1):72-81.

11. Walter JS, Wheeler JS, Cai W, King WW, Wurster RD. Evaluation of a suture electrode for direct bladder stimulation in a lower motor neuron lesioned animal model. IEEE Trans Rehabil Eng. 1999;7(2):159-66.

12. Dalmose AL, Rijkhoff NJ, Anderson IS, Stefania D, Jorgensen TM, Djurhuus JC. Bladder and urethral responses to pelvic nerve stimulation in the pig. Scand J Urol Nephrol Suppl. 2002;210:34-45.

13. Gladh G, Mattsson S, Lindstrom S. Intravesical electrical stimulation in the treatment of micturition dysfunction in children. Neurourol Urodyn. 2003;22:233-42.

14. Cameron T, Richmond FJ, Loeb GE. Effects of regional stimulation using a miniature stimulator implanted in feline posterior biceps femoris. IEEE Trans Biomed Eng. 1998; 45(8):1036-43.

15. Cameron T, Loeb GE, Peck RA, Schulman JH, Strojnik P, Troyk PR. Micromodular implants to provide electrical stimulation of paralyzed muscles and limbs. IEEE Trans Biomed Eng. 1997;44(9):781-90.
16. Cameron T, Liinamaa T, Loeb GE, Richmond FJ. Longterm biocompatibility of a miniature stimulator implanted in feline hind limb muscles. IEEE Trans Biomed Eng. 1998;45(8)1024-35.

17. Loeb GE, Richmond FJ. BION implants for therapeutic and functional electrical stimulation. In: Cain JK, Moxon JA, Gaal G, editors. Neural prostheses for restoration of sensor and motor function. Boca Raton (FL): CRC Press, Inc.; 2001.

18. Loeb GE, Peck RA, Moore WH, Hood K. BION system for distributed neural prosthetic interfaces. Med Eng Phys. 2001;23(1):9-18.

19. Arcos I, Davis R, Fey K, Mishler D, Sanderson D, Tanacs C, Vogel MJ, Wolf R, Zilberman Y, Schulman J. Second-generation microstimulator. Artif Organs. 2002;20(3):228-33.

20. Walter JS, Riedy, LW, King WW, Wheeler JS, Najafi K, Anderson CL, Gudausky TM, Dokmeci M. Short-term bladder wall response to implantation of microstimulators. Spinal Cord Med. 1997;20:319-23.

21. Walter JS, Wheeler JS, Fitzgerald M. Technical perspective: Chronic instrumentation with model microstimulators in an animal model of the lower urinary tract. J Spinal Cord Med. 2005;28(3). In press.

22. Cannon TW, Damaser MS. Effects of anesthesia on cystometry and leak point pressure of the female rat. Life Sci. 2001;69(10):1193-202.

23. Klevmark B. Motility of the urinary bladder in cats during filling at physiological rates. III. Spontaneous rhythmic bladder contractions in the conscious and anesthetized animal. Influence of distention and innervation. Scand J Urol Nephrol. 1980;14(3):219-24.

24. Walter JS, Sidarous R, Robinson CJ, Wheeler JS, Wurster $\mathrm{RD}$. Comparison of direct bladder and sacral nerve stimulation in spinal cats. J Rehabil Res Dev. 1992;29(2):13-22.

25. Cullen WC, Fletcher TF, Bradley WF. Morphometry of the male feline pelvic urethra. J Urol. 1983;129(1):186-89.

26. Hosgood G, Hedlund C. Perineal urethrostomy in cats. Comp Cont Educ Prac Vet. 1992;14:1195-205.

27. Tallala A, Bloom J, Quang N. FES for bladder: direct or indirect means? Pacing Clin Electrophysiol. 1987;10:240-45.

Submitted for publication February 2, 2004. Accepted in revised form September 23, 2004. 